\title{
Impact of Metal Pouring Parameters on Basic Physical Processes
}

\author{
L. SowA*, T. SkrzypczaK And P. KWiatoń \\ Department of Mechanics and Machine Design Fundamentals, \\ Częstochowa University of Technology, 42-201 Częstochowa, Poland \\ Doi: 10.12693/APhysPolA.138.210 \\ *e-mail: $\quad$ sowa@imipkm.pcz.pl
}

\begin{abstract}
The work concerns the use of differential equations to modelling the process of manufacturing machine parts by casting method. A mathematical model describing the course of coupled thermal and flow phenomena in the process of creating an axisymmetric casting was formulated in the paper. The system of partial differential equations has been supplemented with appropriate geometric, boundary, and initial conditions that define the physical problem under consideration. Numerical simulations of the formation of a steel casting were made, starting from the moment of filling the mould cavity with molten metal and ending with complete solidification. During pouring, the forced movement of molten metal dominates, and after filling of the mould cavity, mainly natural convective movements occur. For numerical modelling of the given task, the finite element method was used. The velocity fields were obtained from the solution of the Navier-Stokes equations and the continuity equation, while the temperature fields from the solution of the thermal conductivity equation. In numerical simulations, the pouring temperature and metal pouring velocity were selected in various variants so as to obtain the casting without shrinkage defects. It can be stated that choosing the right variant of pouring parameters is not easy to obtain the casting without shrinkage defects. For most cases, such a defect forms in the upper part of the casting, which we try to avoid when making machine components because this may disqualify them from further use.
\end{abstract}

topics: Navier-Stokes equations, numerical simulations, solidification

\section{Introduction}

The production of a high quality casting demands continuous adjustment of its casting methods. All activities improving casting methods are aimed primarily at obtaining high strength castings without casting defects. Conducting research on real objects is significantly difficult due to the lack of visibility and high temperatures taking place there, which is why computer simulations make it possible to improve casting methods [1-6]. In this article, the process of casting solidification is analysed, considering the phenomena of heat exchange and fluid flow, starting from the moment of filling the metal mould by molten metal and ending with the complete solidification of the casting. The shape of the solidus line is observed, assessing whether it has been closed in the casting area. Such a situation would mean the lack of supply of this area by the liquid metal from the riser and the formation of defects at this place of the casting. We try to avoid this situation by choosing the right velocity and temperature for pouring the molten metal into the mould, which was the purpose of this work.

\section{The mathematical model}

The mathematical description of the casting solidification process considering the liquid metal movements is based on the solution of the following equations system (the Navier-Stokes Eqs. (1), the continuity Eq. (2), the heat conductivity equation with the convection term (3), the first order pure advection Eq. (4)) in a cylindrical axial-symmetric coordinate system [2-6]:

$$
\begin{gathered}
\mu\left(\frac{\partial^{2} v_{r}}{\partial r^{2}}+\frac{1}{r} \frac{\partial v_{r}}{\partial r}+\frac{\partial^{2} v_{r}}{\partial z^{2}}-\frac{v_{r}}{r^{2}}\right)-\frac{\partial p}{\partial r} \\
+\rho g_{r}+\rho g_{r} \beta\left(T-T_{\infty}\right)_{r}=\rho \frac{\mathrm{d} v_{r}}{\mathrm{~d} t}, \\
\mu\left(\frac{\partial^{2} v_{z}}{\partial r^{2}}+\frac{1}{r} \frac{\partial v_{z}}{\partial r}+\frac{\partial^{2} v_{z}}{\partial z^{2}}\right)-\frac{\partial p}{\partial z}+\rho g_{z} \\
+\rho g_{z} \beta\left(T-T_{\infty}\right)=\rho \frac{\mathrm{d} v_{z}}{\mathrm{~d} t}, \\
\frac{\partial v_{r}}{\partial r}+\frac{v_{r}}{r}+\frac{\partial v_{z}}{\partial z}=0, \\
\frac{\lambda}{r} \frac{\partial T}{\partial r}+\frac{\partial}{\partial r}\left(\lambda \frac{\partial T}{\partial r}\right)+\frac{\partial}{\partial z}\left(\lambda \frac{\partial T}{\partial z}\right)= \\
\rho C_{\mathrm{ef}} \frac{\partial T}{\partial t}+\rho C_{\mathrm{ef}}\left(v_{r} \frac{\partial T}{\partial r}+v_{z} \frac{\partial T}{\partial z}\right), \\
\frac{\partial F}{\partial t}+v_{r} \frac{\partial F}{\partial r}+v_{z} \frac{\partial F}{\partial z}=0,
\end{gathered}
$$

where $\lambda-$ the thermal conductivity coefficient $[\mathrm{W} /(\mathrm{mK})], \mu(T)$ - the dynamical viscosity coefficient $[\mathrm{kg} /(\mathrm{ms})], \quad \rho=\rho(T)$ - the density $\left[\mathrm{kg} / \mathrm{m}^{3}\right], \quad v_{r}, \quad v_{z}-$ the $r$-component 


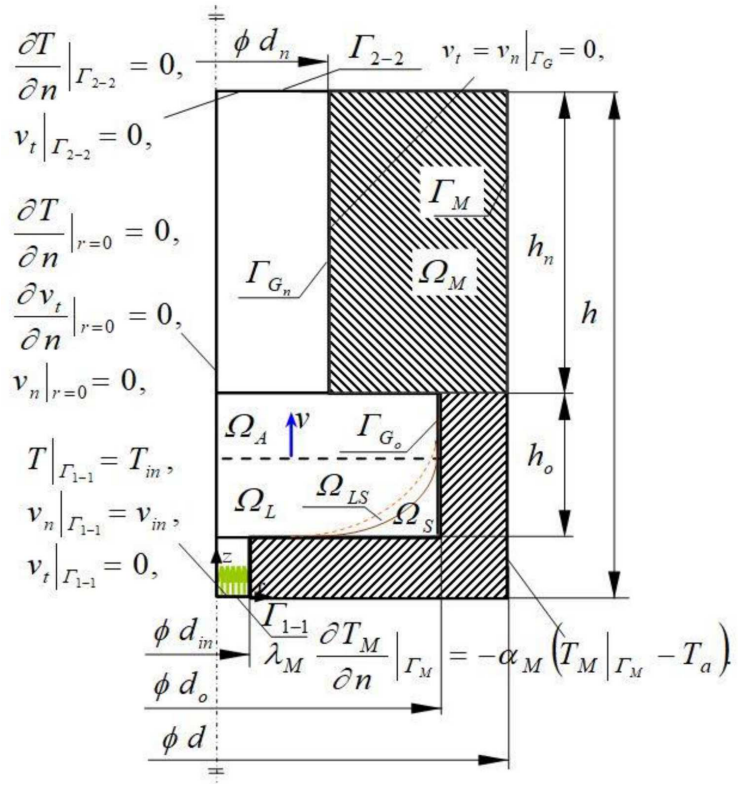

Fig. 1. Boundary conditions, scheme and identification of sub-regions of the considered region.

and $z$-component of velocity, respectively $[\mathrm{m} / \mathrm{s}]$, $T$ - the temperature $[\mathrm{K}], C_{\mathrm{ef}}=c+L /\left(T_{L}-T_{S}\right)-$ the effective specific heat of a mushy zone $[\mathrm{J} /(\mathrm{kgK})]$, $L$ - the latent heat of solidification $[\mathrm{J} / \mathrm{kg}], g_{r}$, $g_{z}$ - the $r$ - and $z$-component of gravitational acceleration, respectively $\left[\mathrm{m} / \mathrm{s}^{2}\right], p-$ the pressure $\left[\mathrm{N} / \mathrm{m}^{2}\right], \beta-$ the volume coefficient of thermal expansion $[1 / \mathrm{K}], t$ - the time $[\mathrm{s}], c$ - the specific heat $[\mathrm{J} /(\mathrm{kg} \mathrm{K})], r$ - the radius $[\mathrm{m}], T_{\infty}$ - the reference temperature $\left(T_{\infty}=T_{i n}\right)[\mathrm{K}], F$ - the pseudoconcentration function across the elements lying on the free surface, $\alpha_{M}$ - the heat transfer coefficient between the ambient and the mould $\left[\mathrm{W} /\left(\mathrm{m}^{2} \mathrm{~K}\right)\right], T_{a}$ - the ambient temperature $[\mathrm{K}], T_{L}, T_{S}$ - the temperature of liquid and solid phase, respectively $[\mathrm{K}]$, $T_{A}$ - the temperature of air inside mould cavity in initial state $[\mathrm{K}], \lambda_{M}$ - the thermal conductivity coefficient of mould $[\mathrm{W} /(\mathrm{m} \mathrm{K})], v_{t}, v_{n}$ - the tangential and normal component of velocity vector, respectively $[\mathrm{m} / \mathrm{s}], n$ - the outward unit normal surface vector.

The system of Eqs. (1)-(4) was supplemented with appropriate initial conditions [5] and boundary conditions, which were assumed on the indicated surfaces (Fig. 1) [3-5]. This task was solved using the finite element method (FEM) in the weighted residuals formulation [3-5].

\section{Examples of numerical calculations}

To analyse the impact of the movements of the liquid metals alloy and pouring conditions on solidification of the casting, the following casting-risermould system was considered (Fig. 1).

The outside mould dimensions are equal to $d=0.320 \mathrm{~m}, h=0.280 \mathrm{~m}$, whereas the mould

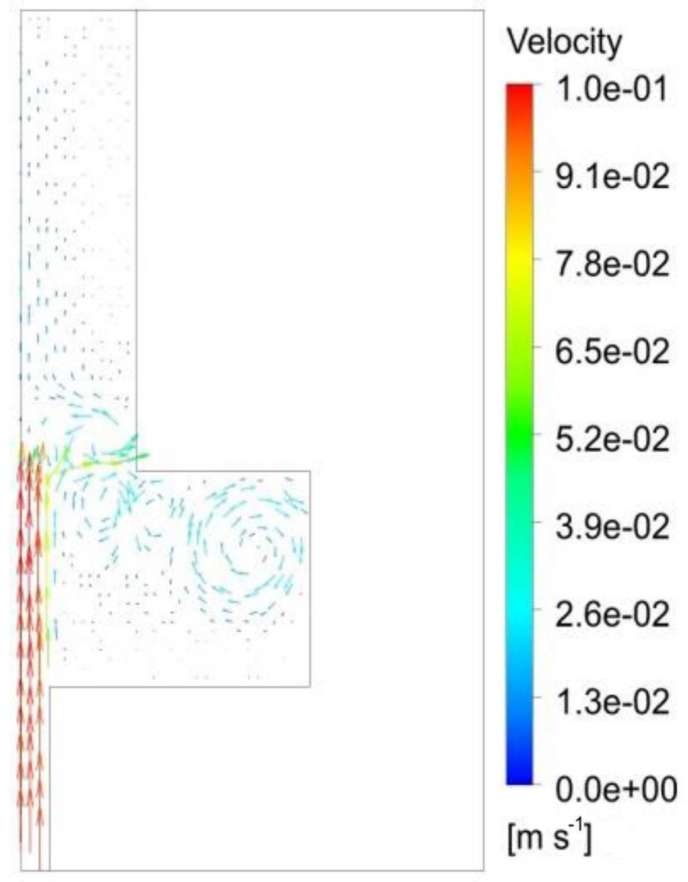

Fig. 2. Velocity vectors at $t=73 \mathrm{~s}, \mathrm{I}$ variant.

cavity dimensions are equal to: $d_{o}=0.200 \mathrm{~m}$, $h_{o}=0.070 \mathrm{~m}, h_{n}=0.150 \mathrm{~m}, d_{n}=0.080 \mathrm{~m}$, $d_{\text {in }}=0.020 \mathrm{~m}$. The internal surface of the steel mould is covered with a protective coating with $2 \mathrm{~mm}$ thickness. The numerical simulations were carried out for the casting made of low-carbon cast steel and the steel mould. The thermo-physical properties were taken from work [5]. The overheated metal with temperature $T_{i n}=1835$ or $1820 \mathrm{~K}$ has been poured from the bottom with the velocity $v_{\text {in }}=0.1$ or $0.2 \mathrm{~m} / \mathrm{s}$, depending on the variant, into the steel mould with initial temperature $T_{M}=350 \mathrm{~K}$. Other important temperatures were equal to $T_{A}=350 \mathrm{~K}, T_{a}=300 \mathrm{~K}$. The heat transfer coefficient $(\alpha)$ between ambient and the mould was equal to $\alpha_{M}=200 \mathrm{~W} /\left(\mathrm{m}^{2} \mathrm{~K}\right)$. The professional Fidap program was used for the calculations. The geometry of system was divided into 4979 quadrilateral elements.

Numerical calculations of the solidification process of the casting-riser system were carried out for different combinations of pouring parameters from which the system of three pairs of velocity and pouring temperature was selected, creating the following variants. In I variant they were $v_{\text {in }}=0.1 \mathrm{~m} / \mathrm{s}$, $T_{\text {in }}=1835 \mathrm{~K}$. In II variant they were equal to $v_{\text {in }}=0.1 \mathrm{~m} / \mathrm{s}, T_{\text {in }}=1820 \mathrm{~K}$ and in III variant they were equivalent to $v_{\text {in }}=0.2 \mathrm{~m} / \mathrm{s}, T_{\text {in }}=1835 \mathrm{~K}$.

The simulations of the casting formation were made, starting from the moment of filling the mould cavity with molten metal and ending with its complete solidification. Filling the mould with liquid metal is shown in the form of velocity vectors for selected moment of time (Fig. 2). After filling, the temperature distribution is shown in Fig. 3, in 


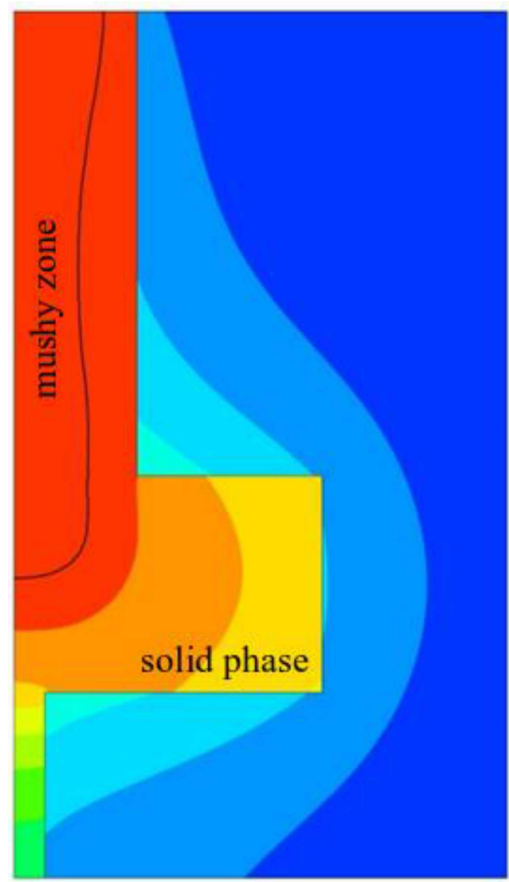

Temp.

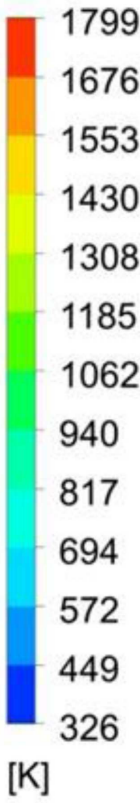

Fig. 3. Temperature distribution at $t=450 \mathrm{~s}$, I variant.
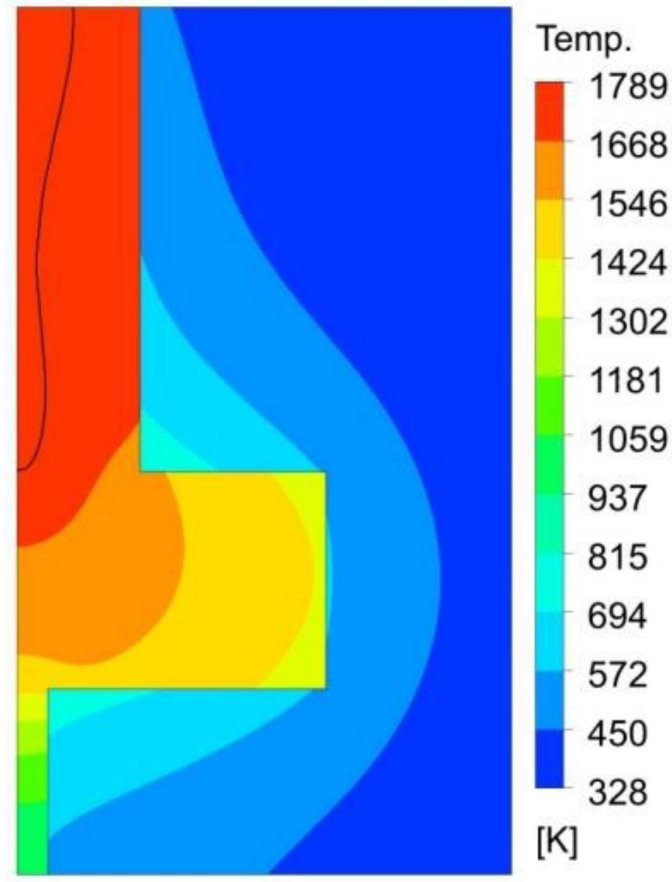

Fig. 4. Temperature field after solidification of the casting $t=514 \mathrm{~s}$, I variant.

which a solidus line was drawn separating the solidliquid area of the casting from its solid area.

Then, the temperature fields after casting solidification were compared for three variants of pouring parameters, observing the shape of the solidus line in the final solidification steps of the casting-riser system (Figs. 4-6). When the solidus line is closed

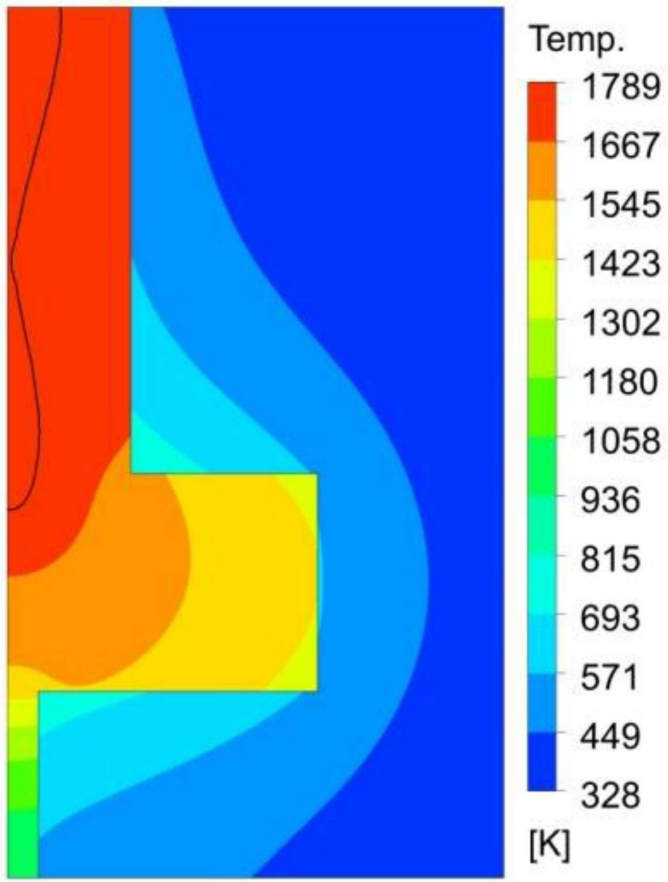

Fig. 5. Temperature field after solidification of the casting $t=490 \mathrm{~s}$, II variant.

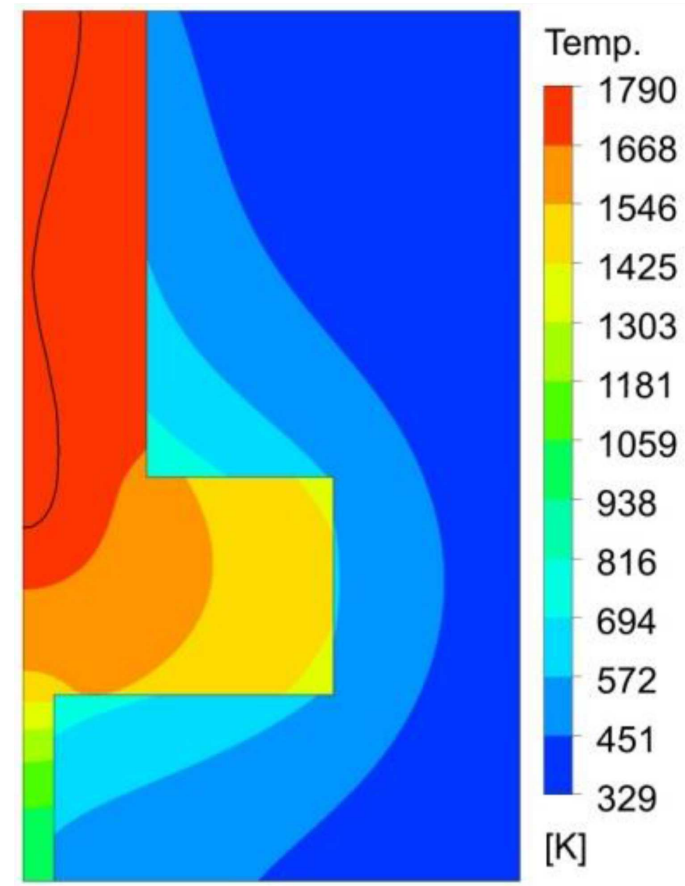

Fig. 6. Temperature field after solidification of the casting: $t=473 \mathrm{~s}$, III variant.

in the casting, the area limited by it will not be fed with liquid metal from the riser and in this place, as a result of metal shrinkage, a shrinkage defect will occur (Figs. 5 and 6). However, we try to avoid such a situation and move such a defect to the riser choosing the right pouring parameters, which was successful in I variant (Fig. 4). 


\section{Conclusions}

The mathematical model and numerical simulation results of the casting solidification which consider filling process of the mould cavity by molten metal were presented in this paper. The influence of molten metal motions on the solidification kinetics and the location of the end of casting solidification were evaluated. The numerical calculations were made for three variants of metal pouring parameters. It has been observed that the solidification process begins effectively for this shape of the casting when the mold cavity is completely filled with liquid metal. However, at the final solidification time of the casting-riser system, the solidus line closed at the upper part of the casting is visible. This suggests the formation of shrinkage defects at this place if the casting process was performed at a reduced pouring temperature or with an increased pouring velocity of molten metal (Figs. 5 and 6). This situation was not observed if casting process was made at standard pouring parameters of the mould cavity (Fig. 4). In this case, the solidification end took place in the riser, which is desired, because the riser is cut off and re-processed. It also proves that the cylindrical-shaped riser executed its task and the casting was made without casting defects.

\section{References}

[1] S.L. Nimbulkar, R.S. Dalu, Perspectiv. Sci. 8, 39 (2016).

[2] P.H. Huang, C.J. Lin, Int. J. Adv. Manufact. Technol. 79, 997 (2015).

[3] R.W. Lewis, E.W. Postek, Z. Han, D.T. Gethin, Int. J. Numer. Methods Heat Fluid Flow 16, 539 (2006).

[4] T. Skrzypczak, L. Sowa, E. WęgrzynSkrzypczak, Archiv. Foundry Eng. 20, 37 (2020).

[5] L. Sowa, T. Skrzypczak, P. Kwiatoń, MATEC Web Conf. 254, 02017 (2019).

[6] P.H. Huang, J.K. Kuo, T.H. Fang, W. Wu, MATEC Web Conf. 185, 00008 (2018). 